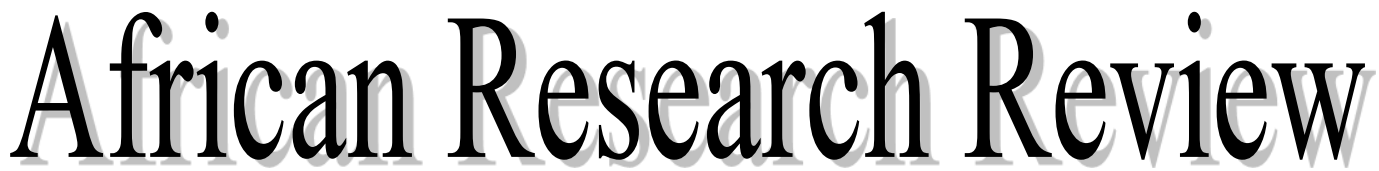

An International Multidisciplinary Journal, Ethiopia

Vol. 10(1), Serial No.40, January, 2016:193-210

ISSN 1994-9057 (Print)

ISSN 2070--0083 (Online)

Doi: http://dx.doi.org/10.4314/afrrev.v10i1.15

\title{
Management of Internally Displaced Persons in Africa: Comparing Nigeria and Cameroon
}

\author{
Eweka, Osagioduwa \\ Peace and Conflict Studies Programme \\ Institute of African Studies \\ University of Ibadan, Ibadan \\ Oyo State, Nigeria \\ Tel: +234(0)7066157781 \\ E-mail: hoxprince@gmail.com; osagioduwaeweka@gmail.com
}

\&

Olusegun, Toluwanimi Oluwakorede

Peace and Conflict Studies Programme,

Institute of African Studies,

University of Ibadan, Ibadan

Oyo State, Nigeria

E-mail: olusegun.toluwanimi@gmail.com

Abstract

According to the Secretary-General of the United Nations, Ban Ki-Moon (2014), Displacement remains arguably the most significant humanitarian challenge facing the world. Of the 33.3 million IDPs in the world, Sub-Saharan Africa hosts 15 million, with an increase of $7.5 \%$ between 2013 and 2014. As the number of IDPs continues to 
increase, attempts at management become more challenging for riddled countries. Notably, global efforts at managing displacement have concentrated more on refugees than IDPs, yet the latter equally constitute a challenge to global civilization. Underpinned by the human needs theory, this study comparatively interrogates the management of internal displacement in Africa with focus on Nigeria and neighbouring Cameroon. The study adopts the quantitative research design, employs survey method for data collection, and simple percentage as well as content analyses techniques for data analysis. With much focus on (dis)similarities in managerial stakeholders and their number, challenges, and degree of success recorded by both countries, it is summed that no one country is more successful than the other in IDPs management, rather both countries have a lot to learn from each other, and there is an urgent need to improve on the management of IDPs in both countries.

Key Words: Cameroon, Conflict, Displacement, Internally Displaced Persons, Nigeria, Peace

\section{Introduction}

Intra-state and intra-regional armed conflicts have continued to result in substantial Internally Displaced Persons (IDP) movements in Africa - the Biafra War in Nigeria (1967-1970); the liberation struggle in Guinea-Bissau (1963-1973); the Casamance Independence Movement in Senegal (1980s till date); the Mauritanian conflict of 1989; the terrible conflict which tore apart the River Mano countries of Sierra Leone and Liberia between 1999 and 2000; the Nigeria-Cameroun Bakassi Peninsula conflict; the post electoral crisis in Ivory Coast (2010-2011); the on-going political crisis in Mali; as well as the on-going Boko Haram insurgency in Nigeria - so have natural disasters too numerous to highlight. According to a 2014 estimate of the Geneva based Internal Displacement Monitoring Centre (IDMC), there are approximately 33.3 million displaced persons (excluding development-induced displacement) across the world, half of which are found in Africa. This suggests that about 15 million people are internally displaced in Africa, and, 9 of the 24 countries with the highest rate of displacement are African (Crisp 2010). In other words, Africa is the continent with the largest number of IDPs in the world. Also, recent studies have shown that sub-Sahara African countries are the richest in the distribution chart, hosting 10.4 million IDPs, with an increase of 7.5\% between 2013 and 2014 (UNHCR 2014). There were 12.5 million IDPs in sub-Saharan Africa as of the end of 2013, which is over one-third of the world's total. Of this figure, Nigeria, accounting for about 3,300,000 IDPs as of March 2014, tops the list of the three countries with the largest population of IDPs in Africa, followed by Democratic Republic of Congo and Sudan, respectively (figures from IDMC), while Cameroon records about 38, 215 IDPs.

Nigeria, particularly, has been finding it increasingly difficult and is almost failing in its task to manage its plethora of IDPs (Olagunju 2006). Obviously, the phenomenon of internal displacement is not new to Nigeria and Cameroon. It is on the 
increase. It portends different dangers for the citizenry and undermines the actualization of the Millennium Sustainable Goals (MSGs). For instance, in Nigeria, the post-election violence of 2011 saw about 65,000 persons internally displaced in the northern part of the country. An estimation by the National Emergency Management Agency (NEMA) reports that from July to October, 2012, a total of 2.1 million residents were sacked by flood in Nigeria. Between January, 2013 and February, 2014, about 470,565 and 143,164 persons were displaced in Nigeria by internal conflicts and natural disasters, respectively, and Internal Displacement cuts across 24 states of the federation. Similarly, between January and March, 2014, insurgency caused the displacement of about 250,000 persons in the northern part of the country alone (Falobi 2014). The Cameroonian experience is not a far cry. Fatal natural and manmade disasters have been hitting the country as far back as the 1980s when carbon dioxide erupted from Lake Nyos, a situation which killed 1,746 and sacked 4,430 residents. Recently, in August and September, 2012, flood emergencies were declared in the North and Extreme North regions of Cameroon and the number of people displaced by flood was about 88,640. Most recently, in April, 2014, an outbreak of cholera was reported in the Far North region of the country, and as of July of the same year, about 1,233 cases were recorded. The result of this was the mass movement of people from the affected area. Between May and mid-June, 2014, about 22,545 persons were evacuated as a result of similar natural disasters in the country (www.reliefweb.int/disasters).

Internally Displaced Persons, upon safe arrival at their new but temporary location, have basic needs such as reasonable shelter, food, potable water, healthcare, education, security, clothing, information, etc. which must be met in order to stay alive and inhibit social-cultural and security consequences both on themselves and host communities alike. Lomo (2000, p. 271) adds that these include issues of physical security, threats of forcible return to region of origin where conditions are not ripe for return, the right to freedom of movement, IDP status determination, and absence of strong, domestic institutional mechanisms for implementing the (inter)national protection regime. As the displaced persons have lost their source of livelihood, resources and savings to disaster, and suffer great hardship (Crisp 2012, p. 1), the government is responsible for providing them with these basic needs during their stay in camp and adopting/implementing policies and techniques on how to manage them except in situations where the State has violated human rights treaties in its treatment of IDPs (Fitzpatrick 2002, p. 5; Plender 1994, p. 356). In so doing, challenges are encountered and lessons learnt. No doubt, lessons learnt in one State could serve as eye-openers for another if well harnessed. To this end, embarking on transnational comparative surveys of management approach of IDPs appears imperative for developing better measures for ameliorating the condition of IDPs in African countries - and beyond. 


\section{Objectives of the Study}

The aim of this research is to compare the management of IDPs in Nigeria and Cameroon. The specific objectives of the research are to:

(i) Determine the challenges associated with management of IDPs in Nigeria and Cameroon.

(ii) Assess the degree of success in the management of IDPs in Nigeria and Cameroon.

(iii) Highlight the similarities and dissimilarities between management of IDPs in Nigeria and Cameroon.

\section{Research Questions}

The following questions have been generated to guide the researcher in his inquisitive expedition:

(i) Why is it difficult to manage IDPs in Nigeria and Cameroon?

(ii) What is the degree of success recorded in IDPs management in Nigeria and Cameroon?

(iii) What are the similarities and dissimilarities in the management of IDPs in Nigeria and Cameroon?

\section{Scope of the Study}

This research is a transnational comparison of the management of Internally Displaced Persons (IDPs). Geographically and temporally, the research is limited to the management of IDPs at the camp sited at the Community Comprehensive Secondary School in Ikot Eyo Edem, Akpabuyo Local Government Area of Cross River State, Nigeria, and the IDPs camp located at the Technical College, Yaoundé, Republic of Cameroon, between 2010 and 2014.

\section{Limitations of the Study}

One major challenge militated against this study. This was the inability to collect primary data from Cameroon respondents through questionnaire. This is attributable to two reasons. Firstly, on arrival at Cameroon, it was discovered that the camp selected for the study which had been the last camp standing had just been closed and all IDPs reintegrated into diverse areas of the country. To overcome this challenge, the researchers succeeded in locating and interviewing a few of the ex-IDPs. Secondly, members of IDPs management agencies who constituted the second sample population were reluctant to supply information. Particularly, they all objected to filling questionnaire but only a few of them granted oral interview, in confidence, mostly on condition of anonymity. 


\section{Significance of the Study}

The findings of this research shall be of benefit to the governments and policy planners of Nigeria and Cameroon in the sense that they shall be resourceful in coming up with improved managerial techniques for handling the internally displaced as well as for tackling the causes and reducing the impacts of internal displacement on citizens. They shall likewise benefit governmental and humanitarian agencies, national and international, that are concerned with the welfare of the internally displaced. Besides, the findings of the research shall help citizens of both countries become well aware of their right not to be displaced. The internally displaced themselves shall gain from the findings of the research: they shall become aware of the rights and privileges accruing to people of their status. Again, the findings of the research shall contribute to knowledge in the field of displacement - especially internal displacement - which appears to have a relatively scanty volume of literature.

\section{Methodology}

This study is quantitative and evaluative. Data for the study were obtained from primary and secondary sources. Documents and interviews were relied upon. Cross River State of Nigeria and Yaoundé of the Republic of Cameroon constituted the study area and two internal displacement camps in both countries were selected for the study. The study population comprised Internally Displaced Persons and staff of governmental and non-governmental management agencies. The study population comprised males and females of fifteen years and above who have been displaced and have found themselves in the chosen IDP camps; members of camp management committees of the various camps studied; Cross River State Emergency Management Agency (SEMA); National Emergency Management Agency (NEMA); the Nigerian and Cameroonian Red Cross Societies; Catholic Relief Agency; Direction de la Prévention des Catastrophes; UNHCR; World Health Organization (WHO) and; Médecins sans Frontières (Doctors without Borders). Two sets of questionnaire were administered to the selected two categories of sample population (IDPs and IDPs management agencies/stakeholders). Of the 300 copies of questionnaire administered to the IDPs in Ikot Eyo Edem camp in Nigeria, 230 were retrieved 30 of-which were found invalid while 200 were found valid for analysis. On the other hand, 250 copies of questionnaire were administered to agencies/stakeholders responsible for management of IDPs. A total of 200 copies were retrieved out of which 40 were found invalid and 160 were found valid for analysis.

Survey and Correlation methods were employed for data collection. Structured format and open-ended questionnaires as well as interview guides designed by the researchers were the instrument used for data collection in this study. The method of data analysis was a combination of qualitative and quantitative methods. The 
quantitative data were analysed using simple percentage analysis of responses to questionnaires, interviews and FGDs; while the qualitative data were content analysed. Suffice it to note that data were collected from Cameroon solely through FGDs and KII. Correlation analysing technique would have been preferable for a comparative study as this but the inability to gather primary data with the use of questionnaire in Cameroon necessitated the choice of simple percentage technique.

\section{Theoretical Underpinning}

This study is anchored by the Human Needs Theory. According to Coate and Rosati (1988), human needs are a powerful source of explanation of human behaviour and social interaction. All individuals have needs they strive to satisfy, either by using the system 'acting on the fringes' or acting as a reformist or a revolutionary. Human needs theory, just a few decades old, was popularized in the works of Abraham Maslow, John Burton, Marshal Rosenberg and Manfred Max-Neef. The theory posits that the basic cause of intractable conflict is the underlying need of people to meet their needs on individual, group and societal bases. According to this theory, human beings need certain essentials if they must live and attain well-being in any ramification of life. Such essentials are known as (basic) human needs. The argument of human needs theorists, therefore, is that the unavailability of alternative means to meet the needs of individuals or groups is what triggers violence - or conflict. Other times, violence also occurs when humans require understanding, respect and consideration for their needs. These needs are not only subsistence ones such as food, water and shelter but also other biological needs such as participation, identity, understanding and recognition (Kok 2007); security, safety, belonging [love], self-esteem and personal fulfilment [life satisfaction] (Maslow 1973).

Burton (1990) who has been applying human needs theory more actively to social and political conflicts looks at how universal human needs often are neglected, causing groups to use violence to claim their rights and satisfy their needs. Marker (2003) believes that unlike interests, needs are untradeable, insuppressible and nonnegotiable. Contrary to the belief that all needs are complementarily essential to human life; no need is inferior to another, Maslow (1973) views some needs as more urgent than others, but agrees that all needs are instinctive. Those he terms more urgent he sees as more powerful too. In his opinion, the powerful needs are subsistence needs such as food, water and shelter which he claims precede all other human needs. As Coate \& Rosati (1988) recommend, 'social systems must be responsive to individual needs, or be subject to instability and forced change (possibly through violence or conflict)'. 


\section{Discussion of Findings}

\section{Challenges Associated with the management of IDPs in Nigeria and Cameroon}

In the perception of respondents, there are a number of challenges associated with IDPs management in Nigeria which are categorized into two, namely structural and cultural challenges. The results indicate that (inadequate) funding; corruption and overlapping/insufficient policies are the principal structural challenges of IDPs management while the host community is the most critical cultural challenge. In the perception of respondents, funding is the most critical among the challenges, followed by corruption.

\section{Funding}

Respondents disclosed that although IDPs management agencies get funds mainly through revenue, international aids and donations, the funds they get are more often than not insufficient to meet the increasing needs of IDPs in the country. Lack or insufficiency of funds results in deficiency in manpower, commodities, infrastructure, equipment and mobility. Olagunju (2006, p. 13) has keenly observed the use of untrained workers by IDPs management agencies. Similarly, Lomo (2000:1) noted that staff members of many institutions, including the UNHCR, are not sufficiently competent to implement existing provisions for protecting the constituencies for whom they are responsible. The majority of the respondents opined that where fund is lacking, standard facilities will be unavailable and the agencies will be inefficient. This is directly linkable to the position of Olagunju (2006, p. 13) that government in Nigeria does not have adequate machinery in place to address IDPs issues and the organizations created by the government possess minimal capacity to handle IDPs related problems. Connected to insufficiency of funds is the problem of low budgeting for emergency. Some respondents rationalized this point by elucidating that emergency is one of the down-scaled components in the budget of key partners both within and outside the government circle.

\section{Corruption}

Respondents equally pointed out corruption as another major challenge impeding effective management of IDPs in Nigeria. While most of the respondents regarded this as the most serious challenge, a large number also regarded it as a very serious one. They maintained that corrupt office holders in government, and in IDPs management agencies alike, have on several occasions been found diverting funds and relief materials meant for IDPs for their personal purposes, a situation that reduces the efficiency of the agencies concerned in managing IDPs. Other respondents, in concordance with Olagunju (2006, p. 28) who found out that government aid (money/relief) gets diverted and never gets to the IDPs themselves, equally traced corrupt practices to camp officials and leaders of IDPs who may also convert and sell 
commodities provided for IDPs thereby contravening principle 24(2) of the $U N$ Guiding Principles on Internal Displacement.

\section{Policies}

Over half of the population interviewed affirmed that policy is a very serious challenge to IDPs management in Nigeria. In the same vein, about $33 \%$ affirmed that it is a fairly serious challenge. Improperly defined, unclear and overlapping policies and institutions have been identified by respondents as problematic to IDPs management agencies as they bring about hindrances and restrictions in discharge of their duties. Another resultant factor is conflict of interest. It was discovered that some of the IDPs management agencies are somewhat ignorant of the specificities of their responsibilities and boundaries while others complained about multiplication and overlap of responsibilities and efforts. Evidently, lack of clarification about jurisdiction of actors would bring about inefficiency in the sense that it would cause delay and slow down the pace of work and also result in lacunae. This finding is analogous with that of Cohen \& Deng (1998) which shows that there is insufficient coordination between actors of management of IDPs. In terms of overlapping institutions, it was noticed from the testimony of key informants from government agencies that the government has established several IDPs management institutions or agencies with similar mandates and structures. A clear example cited by key informants is that of the National Commission for Refugees. In the explanation of one respondent, this institution was originally established and fashioned to cater for refugees in the country and not IDPs, however, some years after its establishment, its mandate was extended to include the responsibilities of NEMA/SEMA and it eventually, nominally metamorphosed into the National Commission for Refugees, Migrants and Internally Displaced Persons. Following documents presented by some key-informant to back -up their claims, it could be deduced that the mandates and organizational structures of the National Commission for Refugees and NEMA are analogous. This probably leaves both establishments with the question of who to do what and what has or has not been done already, and by consequence, a significant part of the job risks being left undone. Additionally, the partnering management agencies like NGOs and humanitarian organizations equally get confused as to which of the two government establishments to be accountable to.

Inversely, two aspects of cultural challenge are discernible from the information supplied by respondents. They are related to the IDPs themselves and the host community. In the perception of respondents, refusal of a person to relocate from his/her usual abode poses a challenge for IDPs management agencies. This occurs mostly when s/he is culturally attached to that place. In the same vein, when s/he eventually agrees to relocate, s/he may not be willing to remain idle but may want to be as active as before. For example, a person who is used to the fishing culture is most likely to leave the camp in search of a river or a brook where they can continue fishing. 
Resulting from indiscriminate movement from the camp may be a (cultural) clash between the IDPs and the host community, a situation which could lead to bloodshed and other health complications inimical to both the IDPs and the host community. Leaving the camp indiscriminately undoubtedly causes problems of management in the sense that there is possibility of IDPs causing troubles of diverse nature in the host community. There is also the possibility of emergence of violent uprisings. Where this is the case, the management agencies may become less efficient as there may be need to divert the little resources available to them in order to resolve such crises. The second aspect of cultural shock is related to the host community.

\section{Host Community}

Respondents have clarified this by explicating that the host community is usually friendly with IDPs until commodities are supplied to the latter. According to some key informants, members of the host community seek to share from the commodities and not being able to achieve this goal may make them frustrated and hostile towards the IDPs. The hostility is said to take different forms ranging from segregation to robbery and other forms of attack. Therefore, in order not to endanger the lives of IDPs who they are mandated to protect, management agencies are usually obligated to cater, to an extent, for members of the host community by letting them have a share of materials meant for the IDPs, thereby shorting their ration. This scenario corresponds with the findings of Ladan (2013) that fractions between IDPs and host communities resulting from concentration of assistance to IDPs and scarcity of resources for distribution are major hindrances to IDPs management.

In Cameroon, respondents highlighted inadequate funding, lack of communication, bad terrain; unpreparedness and host community as the most significant challenge that impede effective management of IDPs.

\section{Inadequate Funding}

The research findings suggest that inadequate funding is a major challenge to management of IDPs in Cameroon. Nearly all the active management agencies in the country depend majorly on international aid and donations. Only few are able to boast of self-generated revenue. Even the UNHCR which is the Chief Agency equally complained of financial constraints and unveiled the level of heaviness of the burden of managing IDPs together with Refugees on UNHCR despite the financial and substantial assistance it gets from other local and international organizations.

\section{Lack of Communication}

Researches have shown that there is a total disconnect between the public and the government in Cameroon. In this case, communicative disconnect is showcased in its height. The reintegrated IDPs interviewed could recall that while they were at the camp, they did not have an effective means through which to communicate directly 
with the management agencies. As a result, there were many instances of misinformation and disinformation pertaining to what was needed and what was supplied. Added to this is that at certain periods when there was delay in supply, the management agencies made no plausible effort to communicate to them the status quo and reasons for the delay. Resultantly, IDPs, impatient, would break out of camp to source for a means of livelihood. This may eventually lead to unmanageable complexities.

\section{Bad Terrain}

According to respondents among IDPs and management agencies alike, bad terrain contributes immensely to the ineffectiveness of management of IDPs in Cameroon. The most significant area where this is felt is in transportation. From findings, it was observed that there are seldom good roads to transport goods and manpower to the camp. The roads are so bad that even the relatively accessible part would cause vehicles to breakdown. Respondents also asserted that supplies were carried manually form the dead end of the road to the camp, a distance of about 15 minutes, owing to inaccessibility. To this end, in times of emergency, vehicles were unavailable to transport patients to health centres. This of course is a risk to the lives of IDPs.

\section{Host Community}

The host community members consider themselves entitled to benefits enjoyed by IDPs. Each time commodities are being transported to camp; able bodied youths would mount road blocks and toll barricades and insist on getting their share of the commodities. Left with little or no alternative, the humanitarian agents would have to part with some (usually a large part) of the commodities; and sometimes cash in lieu of commodities. Humanitarian workers interviewed stressed that it is wise to always give in to the members of the host communities in order for peace to subsequently reign in the IDPs camp.

\section{Unpreparedness}

Respondents also referred to this as early warning defects. It has to do with lack of readiness on the part of the government and by extension humanitarian agencies. As such, the problem of displacement catches them unawares and throws them off balance. Since the causes of displacement are unpredictable in nature, one cannot tell when, where and how exactly they occur and one cannot tell how much funds and manpower will be required either, hence the need for a contingency plan. Deplorably, the government of Cameroon and its partners, in the perception of respondents, fail to make such plans. It appears that they are reactive rather than proactive as far as the issue of displacement is concerned. Emergency preparedness is the fourth element in the Disaster Risk Management Policy Framework for emergency 
management proposed by Ramirez and Rubiano (2009) and adaptable to IDPs management. According to the pair, actions which would include early warning systems, logistics, communication and training should be designed to develop response capacity and ensure effective emergency response - in this case, to ensure effective IDPs management in case of displacement. Also adaptable to IDPs management in Cameroon is the status quo in many sub-Saharan African States observed by Olagunju (2006, p. 29) where government is usually caught unawares by the IDP situation and there is hardly anything to show that the government is better in its planning and preparedness than it may have been yesteryears. He further buttressed the need for leaders to be more proactive at all times as it relates to IDPs management in particular and emergency/disaster in general. Contextually, preparedness implies measures taken in advance to ensure an effective response to the impact of disaster which most often than not results in displacement.

\section{Degree of Success in IDPs Management in Nigeria and Cameroon}

In this study, the degree of success in the management of IDPs in Nigeria and Cameroon was measured by what the management agencies provide for the IDPs, how satisfied the IDPs are and adherence to the UN Guiding Principles of Internal Displacement. In Nigeria, the responses provided by participants from the selected sample population show that the management agencies provide healthcare, food, shelter, education, potable water and security for IDPs in the selected camp for this study. Although the management agencies claim to provide reintegration for IDPs, the IDPs themselves refuted this claim. The Zonal Coordinator of NEMA, South-South Zone, remarked that the period between 2010 and 2014 has been a challenging period in terms of disaster. He also stated that the response of the management agencies responsible for IDPs in the country have been impressive and remarkable. Further, he asserted that as far as the South-South is concerned, IDPs in the Ikot Eyo Edem camp are the only IDPs yet to be reintegrated. He further added that modalities are currently in place to see to their reintegration. Aligning with this view, one respondent from Cross River state SEMA stated that he would grade the management agencies 65-70\% in terms of effective management of IDPs in Nigeria. Apparently, the findings of this research showed that IDPs are satisfied with the provisions for feeding made by the management agencies. Those who gave their opinion affirmed that they feed two times daily and that they are not malnourished. Regarding healthcare, all the respondents interviewed agreed that the prevalent ailment in the camp is malaria fever. Furthermore, they agreed that they receive prompt treatment each time they fall sick. As a matter of fact, there is a stand-by nurse in the camp mandated to monitor the health of the IDPs and also to administer drugs to them whenever necessary.

In terms of professional activeness, over half of the respondents affirmed that they are not practicing their profession owing to lack of equipment, tools and other relevant facilities to enable them do so. On the other hand, $30 \%$ agreed that they 
practice their profession as they are employed by members of the host community who provide them with needed equipment for that purpose. By and large, if the findings of Ladan (2003) are anything to go by, this is not a sign of good success on the part of IDPs management agencies in Nigeria since they have not fully fulfilled principle $22 \mathrm{~b}$ of the Guiding Principles. Therefore, productive people have been rendered redundant. Similarly, from the interviews conducted, the IDPs seem satisfied with their religious status. Almost all of those who responded to interviews and questionnaire admitted that they practice their religion to the fullest. Others who dissented claimed that lack of clothing was responsible for their inability to practice their religion. Thus, it could be said that success has been recorded in the aspect of religious practice by IDPs as stipulated in principle 22a of the Guiding Principles. Concerning security, the results show that the camp is guarded by a joint task force comprising the SSS, NSCDC and IDPs Vigilante Group, and from the findings, it could be deduced that the IDPs in the selected camp are satisfied with the security situation of the camp inasmuch as all the respondents were in unanimity that there has never been a case of armed robbery or other attacks on them since their arrival at the camp. By implication, IDPs management in Nigeria could be adjudged successful based on principle 3(1), 4(1), 10(2) and 14. It is also the case for principle 18, 19,22(a \& c), 23 and 25(1\&2). Conversely, it could be adjudged unsuccessful when one considers the country's contravention of principles 24(2) and 25(3) of the Guiding Principles. Reintegration is one aspect where the IDPs have expressed full dissatisfaction. Respondents expressed their fears that they may just be headed towards limbo since none of them, not even one, has been reintegrated since arrival at the camp in 2013. In their opinion, it is either the government is not doing enough to reintegrate them or they have been incommunicado about their reintegration plan(s). Nevertheless, in the rating of respondents, government agencies are the most effective of the IDPs management agencies in Nigeria.

The success of IDPs management in Cameroon was more difficult to ascertain on the field because of difficulty in getting a tangible number of IDPs to respond to interviews and questionnaire. Ironically, the difficulty in getting the opinion of IDPs due to the fact that they have been reintegrated is, to a measure, proof of success in IDPs management. The few ex-IDPs who aired their views recalled that the IDPs were satisfied with the feeding, healthcare and professional and religious activeness they enjoyed while in the camp. On the other hand, they were dissatisfied with the security situation in the camp as they lamented the recorded cases of armed attacks on them. On that which concerns reintegration, they unveiled their satisfaction, stating that they currently enjoy decent accommodation, health facilities and self-employment, thanks to IDPs management agencies, particularly UNHCR which in their estimation is the most effective of all the IDPs management agencies in the country. Measuring the degree of success in IDPs management in Cameroon, it appears that the government of Cameroon contravenes principle 3(1) and 25(1) where it seems to have ceded its 
responsibility to manage its IDPs to UNHCR which is an international, humanitarian organization. In like manner, there is seemingly no record of success where the government failed to provide security and education for IDPs as stated in principle $10(2 \mathrm{a} \& \mathrm{~d})$ and 23 , respectively. It is worth mentioning here that past researches in this field have divulged that humanitarian NGOs local or otherwise can only do so much in the absence of a supportive government. On the other hand, it is noteworthy to mention the success recorded for Cameroon by adherence to principle 18 of the Guiding Principles which provides standards for provision of basic needs. Same could be said in relation to principles $19 ; 22 ; 24$ and $25(2 \& 3)$ which concern healthcare, free exercise of religion and profession and non-interference in discharge of humanitarian activities, respectively.

\section{Management of IDPs in Nigeria and Cameroon: Similarities and Dissimilarities}

Results clearly show that there are similarities and dissimilarities between management of IDPs in Nigeria and Cameroon as obvious in the agencies responsible for IDPs management, the strategies employed in managing IDPs, the challenges associated with IDPs management and the degree of success in the management of IDPs shall be navigated in this section of the study.

\section{Similarities}

The very first observable similarity between IDPs management in Nigeria and Cameroon is found in the management agencies. In both countries, the management agencies are of three distinct categories namely government agencies, humanitarian agencies, religious organizations and NGOs. In addition, the main actors in both countries are analogous. They are the Red Cross Society, Doctors without Borders, WHO, UNHCR and UNICEF and they have all been in existence in each of the countries for over six years. Another area of convergence in IDPs management between both countries is in supply of commodities. Just like in Nigeria, management agencies in Cameroon provide certain basic needs of IDPs such as food, shelter, healthcare and potable water. Management of IDPs is also similar in terms of strategies employed. For example, in both countries, there is a head agency responsible for coordinating all others and collaboration equally comes into play. Government ministries, humanitarian organisations and NGOs join hands together to ease the plights of IDPs. Additionally, steps taken to palliate the sufferings of IDPs are similar. These are responsive or reactive steps which begin with establishing a camp and ends with reintegration. For instance, the Red Cross is responsible for dealing directly with the IDPs on health matters and they collaborate with WHO, UNICEF and Doctors without Borders. Correspondingly, SEMA/NEMA collaborates with ministry of Agriculture in Nigeria, and then in Cameroon, UNHCR does same to provide food for the IDPs.

From the findings of this study, it could be inferred that IDPs management agencies in both countries generate funds through like means: international aid and 
donations. In like manner, the findings equally suggest that they both share the problem of insufficiency of funds in common, a situation which in no small measure limits their capacity to perform efficiently. Apart from funding, IDPs management agencies in each of the countries in contrast face challenges emanating from the host community. Further, measuring the degree of success of IDPs management agencies in both countries by successful reintegration of IDPs would reveal that both countries, as shown by the results of this study, have reintegrated a number of IDPs within the studied period $(2010-2014)$. By the same token, measuring the degree of success of IDPs management agencies in both countries by the satisfaction of IDPs, it appears that both countries are on the same success page given that IDPs in both countries agreed that they were satisfied with basic needs like feeding, healthcare, professional activeness and religious activeness. Another glaring similarity brought to the fore by the findings of this research is that both Nigeria and Cameroon tend to be reactive rather than proactive in matters concerning IDPs management. This point tallies with the findings of Maduka (2012, p. 88) that most responses to disaster in Nigeria are often reactive and only limited to the immediate containment of the humanitarian crises without follow ups or long term reconstruction or rehabilitation initiatives. This research has discovered that this trait is equally true about Cameroon.

\section{Dissimilarities}

The first striking dissimilarity between IDPs management in Nigeria and Cameroon is the number of management agencies that exist in the two countries. As respondents estimated, while Nigeria accounts for over 20 of these management agencies, Cameroon accounts for at least 50. Majority of these agencies are international and are affiliated to UNHCR, WHO and other major players in the international humanitarian scene. This brings to bare the fact that compared to Cameroon, international response in Nigeria has been rather inadequate. It was observed from the findings herein that unlike what obtains in Nigeria, individual philanthropists scarcely play a role in the management of IDPs in Cameroon. In like manner, Teachers without Borders does not belong to the frontline agencies in charge of IDPs management in the country. Furthermore, in hierarchy, UNHCR is the chief agency in charge of IDPs management in Cameroon and it coordinates all others with little or no interference from the government while government agencies merely play an observatory cum documentary role. Testimonies from participants imply that the country has failed in its obligations towards its IDPs and as a result, the recommendation of Cohen \& Deng (1998), which states that where a state fails to meet its obligations and refuses to accept outside assistance, the international community should assert its concern and step in, consciously or unconsciously came into full implementation. This is different from the Nigerian scenario where government agencies (NEMA/SEMA) coordinate the other agencies and are hierarchically over and above them and inversely, UNHCR is barely active. 
Moreover, unlike in Nigeria, IDPs in Cameroon do not receive formal and informal education. Same is true of security. Accounts of respondents point to the fact that security agents were not provided to guard the camp prior to its closure. However, they have recently been provided with reintegration which they seem to be satisfied with. As results of this study suggested, another area of dissimilarity is challenges associated with IDPs management. While IDPs management agencies in Nigeria encounter challenges of corruption and policies, those in Cameroon do not, or they do rather minimally. The result of this study shows that there are firmer and clear-cut policies on IDPs management in Cameroon. Fundamentally, it appears that placing UNHCR, an international humanitarian organization at the herm of affairs has helped to check corruption in the system. Inversely, it appears that lack of communication is least of the problems encountered in the course of managing IDPs in Nigeria. Respondents in Nigeria did not identify lack of communication as a major challenge. By the same token, bad terrain and unpreparedness highlighted by respondents as some of the most serious challenges to IDP management in Cameroon are rare in Nigeria. This is not to say that the terrains in Nigeria are perfect, or that Nigeria is ever prepared for outbreak of displacement, but the government appears to have a more solid structure which enables agencies respond relatively more promptly and relatively more effectively to eventualities. To this end, the Nigerian government seems more proactive than its Cameroon counterpart.

\section{Conclusion}

The need to properly manage IDPs in Nigeria and Cameroon cannot be overemphasized inasmuch as improper management of the group may make the countries prone to violent conflicts and other several complexities such as epidemics. However, the management of IDPs cannot be left in the hands of any one individual or group. It appears that collaboration is the name of the game. The major points of divergence between management of IDPs in Nigeria and Cameroon may include the fact that government agencies are the most efficient in IDPs management in Nigeria while the UNHCR is in Cameroon. Apparently, international response to IDPs management in Nigeria has been largely inadequate. The government of Cameroon, unlike Nigeria's, has practically handed the management of its IDPs fully to the UNHCR which also coordinates other management agencies for that purpose. This is in contradiction with principle 3(1) of the UN Guiding Principles of Internal Displacement. It suffices to add that this may account for the speedy reintegration of IDPs in the country. Tied to this is the direct contact of IDPs management with IDPs themselves rather than through the government or governmental agencies, what does not seem to obtain in Nigeria. Two basic yardsticks come into play when determining the overall success of IDPs. The first is the provision of the United Nations Guiding Principles on Internal displacement while the second is reintegration of IDPs. Apparently, management agencies in both countries have contravened and observed 
alike some of the UN Guiding Principles. Therefore, considering the success of Nigeria and Cameroon in management of IDPs in line with the first yardstick, it could be deduced that Nigeria is more successful than Cameroon for the fact that the latter has contravened more of the Guiding Principles than the former. In the inverse, it is evident that Cameroon is more successful if we consider the second yardstick (reintegration). After all, many a scholar such as Maduka $(2012$, p. 87) has noted that reintegration which is the final and concluding stage of IDPs management ultimately seeks to support people rebuild their livelihoods including housing, sources of income, economic, social and cultural activities as well as general standard of living. In this regard, the Nigerian government still has a lot to do. To this end, no one country can categorically be pronounced more successful than the other in management of IDPs.

\section{Recommendations}

In order to enhance the management of IDPs in Nigeria and Cameroon, certain recommendations have been derived from data presented and findings of this study.

1. Governments of Nigeria and Cameroon should enact a local law in the various countries to compel IDPs management agencies at all levels to stringently observe the UN Guiding Principles on Internal Displacement to the letter. In the alternative, they should adapt these principles as national laws and make them binding on all IDPs management agencies.

2. The Nigerian government should fight corruption and ensure a direct link between the management agencies and the IDPs. The role of intermediary played by government agencies such as NEMA and SEMA should be discouraged, and in fact, discontinued.

3. To make funds available for the management of IDPs in Nigeria and Cameroon, governments of both countries should solicit for donations and financial aids from more international bodies. They should also collaborate with more international humanitarian organizations.

4. The budgetary allocation for displacement in both countries should be separated from allocation for disaster and/or emergency since not all disasters and emergencies result in displacement. If this is done, there is a high likelihood of more financial concentration and commitment to IDPs situation in the countries.

5. Contingency plans should be made financially and bureaucratically in preparation for events of displacement. The bureaucratic process involved in the release of funds and other resources for management of IDPs should be simplified to suit the sudden nature of displacement. 
6. The Nigerian government should ensure strict, decisive and clear-cut policies on IDPs management in order to avoid ambiguity in roles and boundaries of IDPs management agencies.

7. In addition to the above, the Nigerian government should avoid multiplicity of parallel policies and agencies of parallel jurisdiction. This will will help in clearly defining the role(s) and boundaries of each management agency.

8. Governments of Nigeria and Cameroon should collaborate with all stakeholders of IDPs management to sensitize the host communities on the need to keep off troubles and be hospitable towards IDPs instead. If possible, they should also factor-in the host communities into the budgeting of IDPs. By this, the host communities are most likely to be more cooperative with both the IDPs and their managers alike.

9. Governments of Nigeria and Cameroon should endeavour to be proactive rather than responsive or even retroactive. Designated safe areas should be set aside for displacement even before they occur irrespective of the ability of government to develop or maintain them. Possibly, permanent structures do not necessarily have to be erected in these areas. An expanse of land may be reserved in case of displacement and when it eventually occurs, quality tents could be set up to temporarily accommodate the displaced.

10. Particularly for the case of Cameroon where bad terrain is a challenge to effective IDPs management, a liaison office and warehouse should be located very close to camps while members of IDPs management agencies who form part of displacement committee should be made to live in or close to the camp.

\section{References}

Burton, J. (1990). Conflict: Resolution and prevention. New York: St. Martin's Press.

Coate, R. A., Rosati, J. A. (eds.) (1988). Preface. The power of human needs in world societies. ix Boulder Co: Lynne Rienner.

Cohen, R. (2007). Response to Hathaway. Journal of Refugee Studies 20, 270-312.

Cohen, R., Deng, F. (1998). Masses in flight: The global crisis of internal displacement. International Review of the Red Cross 835.

Crisp, J. (2012). Forced displacement in Africa: Dimensions, difficulties and policy directions. Refugee Survey Quarterly. Available from: www.oxfordjournals.org [Accessed 20 August, 2014].

Falobi, F. (2014). Nigeria: Coping with challenges of internally displaced persons. Allafrica. Available from: www.m.allafrica.com [Accessed 15 August, 2014.] 
Fitzpatrick, J. (ed.) (2002). Human rights protection for refugees, asylum-seekers and internationally displaced persons: A guide to international mechanisms and procedures. New York: Transitional. http://www.reliefweb.int/disasters. [Accessed 15 August, 2014]

IDMC (2008). Internal displacement: Global overview of trends and developments in 2008. Available from: http://www.interna-displacement.org [Accessed 14 September, 2014].

Kok, H. (2007). Reducing violence: Applying the human needs theory to the conflict. Review of International Law and Politics, 3 (11), 89-108.

Ladan, M. T. (2013). National Framework for the Protection of Internally Displaced Persons (IDPs) in Nigeria: A paper presented at a workshop for judges and kadis on Refugee Law organised by National Institute, Abuja, Nigeria. $20^{\text {th }}$ April, 2013.

Lomo, Z. (2000). The struggle for protection of the rights of refugees and internally displaced persons in Africa: Making the existing international legal regime work. Berkeley Journal of International Law, 18 (2), Article 8.

Marker, S. (2003). What human needs are. Beyond intractability. Available from: http://beyondintractability.org/m/huma_needs.jsp [Accessed 28 August, 2014].

Maduka, E. I. (2012). Responses to ecological disaster induced displacement in Anambra State. Unpublished thesis. University of Ibadan.

Maslow, A. (1973). The further reaches of human nature. Harmondworth: Penguin Books.

Olagunju, O. (2006). Management of internal displacement in Nigeria. Unpublished thesis. Brandeis University.

Omole, M. A. (2012). An assessment of the challenges of internally displaced persons in the post-election violence of Kenya: A case study of 2007-2008. Unpublished thesis. University of Ibadan.

Plender, R. (1994). The legal basis of international jurisdiction to act with regard to the internally displaced. International Journal of Refugee Law, 3, 345: 356.

UNHCR (2009). Global appeal Update. P.40.

UNHCR (2009). Global trends: Refugees, asylum seekers, returnees, internally displaced and stateless persons 2. Available from: http://www.unhcr.org/4a275c426html [Accessed 30 August, 2014]. 